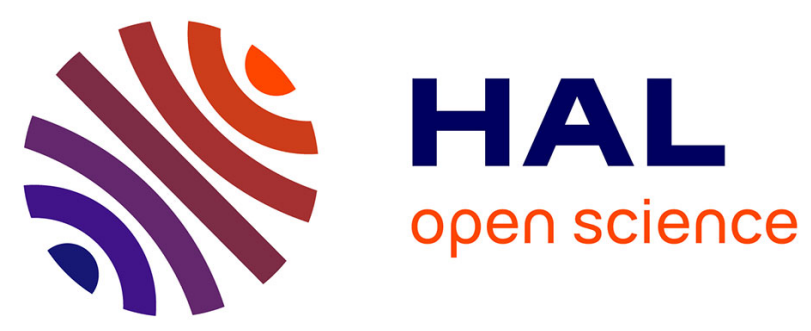

\title{
Sense of identity in advanced Alzheimer's dementia: a cognitive dissociation between sameness and selfhood?
}

\author{
Marie-Lou Eustache, Mickael Laisney, Aurelija Juskenaite, Odile Letortu,
} Hervé Platel, Francis Eustache, Béatrice Desgranges

\section{- To cite this version:}

Marie-Lou Eustache, Mickael Laisney, Aurelija Juskenaite, Odile Letortu, Hervé Platel, et al.. Sense of identity in advanced Alzheimer's dementia: a cognitive dissociation between sameness and selfhood? Consciousness and Cognition, 2013, pp.1. inserm-00874387

\section{HAL Id: inserm-00874387 https://www.hal.inserm.fr/inserm-00874387}

Submitted on 17 Oct 2013

HAL is a multi-disciplinary open access archive for the deposit and dissemination of scientific research documents, whether they are published or not. The documents may come from teaching and research institutions in France or abroad, or from public or private research centers.
L'archive ouverte pluridisciplinaire HAL, est destinée au dépôt et à la diffusion de documents scientifiques de niveau recherche, publiés ou non, émanant des établissements d'enseignement et de recherche français ou étrangers, des laboratoires publics ou privés. 


\section{Sense of identity in advanced Alzheimer's dementia: a cognitive dissociation between sameness and selfhood?}

Eustache, ${ }^{*}$ M.-L. ${ }^{\text {abcd }}$, Laisney, ${ }^{*}$ M. ${ }^{\text {abcd }}$, Juskenaite, A. ${ }^{\text {abcd }}$, Letortu, O. ${ }^{\text {e }}$ Platel, H. ${ }^{\text {abcd }}$, Eustache, F. $^{\text {abcd }}$, Desgranges, B. ${ }^{\text {abcd }}$

*These authors contributed equally to this work

${ }^{\mathrm{a}}$ Inserm, U1077, Caen, France

${ }^{\mathrm{b}}$ Université de Caen Basse-Normandie, UMR-S1077, Caen, France

${ }^{c}$ Ecole Pratique des Hautes Etudes, UMR-S1077, Caen, France

${ }^{\mathrm{d}} \mathrm{CHU}$ de Caen, UMR S1077, Caen, France

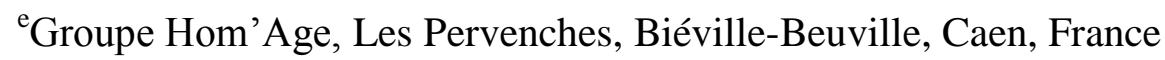

Corresponding author: Dr Béatrice DESGRANGES

desgranges-b@chu-caen.fr

Inserm-EPHE-UCBN U1077

CHU de CAEN

Avenue de la Côte de Nacre

CS 30001

F-14033 CAEN CEDEX 9

Tel.: +33231063261

Fax: +33231065198 


\begin{abstract}
We looked at whether sense of identity persists in patients with Alzheimer's disease (AD) and if its profile remains the same between two examinations. A specifically designed protocol was administered to $16 \mathrm{AD}$ patients in the mild to severe stages of dementia and to 16 matched healthy controls, both living in the same institution. We showed that sense of identity was broadly preserved in $\mathrm{AD}$ patients. The patterns of their responses were similar to those of controls, and remained consistent over a two-week period. However, some qualitative characteristics of sense of identity in $\mathrm{AD}$ patients differed significantly from those of controls, suggesting that $\mathrm{AD}$ patients may not be able to update their self-knowledge, probably because of their episodic memory deficit. These results are discussed in the light of both current models of the self and philosophical concepts such as sameness and selfhood.
\end{abstract}

\title{
Keywords
}

Self, Dementia, Sense of Identity, Alzheimer's disease, Sameness, Selfhood

\section{Highlights}

- Sense of identity is partly preserved even in advanced stage of Alzheimer's dementia.

- Patients' self-descriptions remained consistent over a two-week period.

- Alzheimer's dementia patients may not be able to update their self-knowledge.

- Our findings fit with philosophical concepts such as sameness and selfhood.

- The fact of feeling the same, i.e. sameness, is preserved in Alzheimer's disease. 


\section{Introduction}

According to the philosopher Edmund Husserl (1913/1950), the self is a spectator of itself and of the world. The self requires sustenance from others and from its environment to develop itself and continue to flourish over time. It also feeds on what it sees about itself, what it remembers and what it chooses to remember (Husserl, 1893-1917/2003). Trying to give a complete definition of the self is problematic and may lead to divergent theories, because the self is multifaceted itself, being a function of time, of others and concurrently remaining the same, as it can also be defined as the permanent conservation of oneself. In his conception of the self, the philosopher Paul Ricoeur (1990) emphasizes the constant updating of the Self, contesting Locke's vision of a permanent self (1689/2001). Thus one could characterize oneself in two different ways: by referring either to the core (and basic) aspects of oneself or to the more labile ones. These to manners to describe oneself echo philosophical concepts of sameness and selfhood, referring respectively to the fact of feeling the same, no matter one's own social status, period of life or health issues, and the fact of being in a permanent alteration, thus being somebody precise on this very moment and different from who one was yesterday. Therefore there could be two types of "self", one, more general, core and constant and the other modulated by time and different experiences. Just as time seems to be a fundamental concept for trying to grasp the essence of the self, so memory can be regarded as a bridge leading to its understanding. Although the self is more than memory, in the past few years a growing number of researchers have viewed autobiographical memory as a means of capturing the nature and functioning of the self.

In psychology, the self is viewed as a complex multi-dimensional construct with a structural level of self-representation in memory (Kihlstrom, Beer \& Klein, 2002) and a set of self-related functional processes required to evoke self-representations (Morin, 2006; Stuss, 
Gallup \& Alexander, 2001). Self-representations, which give rise to the sense of identity, consist of personal information, stored in either semantic or episodic autobiographical memory (Klein, 2010). Semantic self-representations include not only general knowledge of personal significance (e.g., "I was born in Paris") and semantic autobiographical memories (e.g., "When I was young, I used to go on holiday in Brittany"), but also abstract trait selfknowledge (e.g., "I am an ambitious person") and knowledge about more private (covert) aspects of oneself, such as internal attributes (e.g., "I pay close attention to my feelings"). Trait self-knowledge defines our identity and personality (Haslam et al., 2011, Klein, Loftus, \& Kihlstrom, 1996). Trait self-knowledge can be broken down into a number of different domains, including physical, psychological, and social, etc. (Byrne, 1996, Fitts \& Warren, 1996). Contrary to semantic self-representations (e.g. "I am helpful"), episodic selfrepresentations consist of more concrete and specific items of personal information referring to a specific spatial and temporal context (e.g., "Yesterday at the supermarket, I helped someone pick up her shopping after her bag broke") (Conway, 2009; Piolino, Desgranges, \& Eustache, 2009; Tulving, 2002).

If autobiographical memory is indeed crucial to the construction of the sense of identity and the feeling of self-continuity (Conway, 2005), what happens to sense of identity in patients suffering from severe episodic memory disorders and who are thus unable to relive personal events with "warmth and intimacy", to quote William James (1890)? Patient KC, who suffered from severe amnesia, was unable to remember any specific, personally colored life experiences, but had relatively well preserved semantic autobiographical memory (Tulving, 1993). KC also underwent a profound change of personality but, interestingly, possessed "reasonably realistic trait self-knowledge", corresponding to his present self, indicating that he had acquired new trait self-knowledge. Furthermore, this study and others (see Klein \& Lax, 2010, for a review) suggest that even when episodic self-representations are 
lost in dense amnesic syndromes, sense of identity can still survive on semantic selfrepresentations. Determining the integrity of sense of identity is extremely worthwhile both at the theoretical level and in terms of patient care (see Caddell and Clare, 2011a, for a review of the interventions supporting self in dementia). However, it is particularly hard to accomplish in Alzheimer's dementia, which is characterized by particularly severe disorders of episodic memory from the onset of the disease, as well as by semantic memory disturbance that can be significant by the time the patient has reached the moderate stage. Indeed, it is legitimate to wonder whether the residual semantic memory is sufficient to ensure the persistence of sense of identity in these patients.

Studies devoted to the self in dementia have used both qualitative and quantitative measures and have been founded on a variety of theories (see Caddell and Clare, 2010, for a review). Qualitative approaches based on analyses of verbal interactions involving patients have mainly explored the self as a unitary construct in the context of different models such as the social constructionist model (Sabat and Collins, 1999) or interactionist models of self. On the contrary, quantitative approaches have been designed to measure a specific component of the self such as self-knowledge (Gil et al., 2001), role identities (Cohen-Mansfield et al., 2000), self-recognition (Heman et al., 2005) and the identity component of the self-concept (Addis and Tippett, 2004). Studies of the self in Alzheimer's disease (AD) are scarce and the methodologies used vary widely. There is a genuine debate between scientists on this subject not yet sufficiently explored according to Caddell and Clare (2010). Some claim that the self disintegrates as the disease progresses, whereas others argue that it persists, at least in a partial form. Davis (2004), for instance, talked about the "dismantling of the self" and the "dissolution of personality", and hypothesized the progressive and complete loss of self with the advancement of dementia. By contrast, Fazio and Mitchell (2009) investigated the persistence of self in people with $\mathrm{AD}$ via visual self-recognition using photographs. These 
authors showed that, even though they had no memory of a photographic session they had undergone only minutes earlier, all the participants with mild impairment and most of those with moderate impairment were able to identify the person in the photograph that had just been taken as themselves, consistent with a relatively well preserved self. The same conclusion was reached in the other part of the study, which examined the use of personal pronouns and attributes elicited in a semi-structured interview: when the rate of production was considered, the mean numbers of pronouns and attributes produced per minute were very similar for AD patients and for controls. Caddell and Clare (2013) reported that AD patients in the mild stage of the disease felt that little had changed considering their identities as a whole, even if most features they identified about themselves were different from those that characterized them prior to the onset of the disease. Most researchers are supporters of an inbetween thesis. For instance, Hehman, German, and Klein (2005) asked Patient PH, who was in the severe stage of Alzheimer's dementia, scoring 7 on the Mini-Mental State Examination (MMSE; Folstein et al., 1975), to identify herself in a series of pictures from each decade of her life, representing her in her 20s, 30s, 40s, 50s, 60s, 70s, and 80s. PH was able to recognize herself in photographs taken during her early life, but not in pictures taken during the last decades of her life. According to the authors, this suggested that PH's failure to update her semantic self-knowledge could be ascribed to a temporally graded breakdown in semantic memory. Fargeau et al. (2010) examined three domains of self in line with James' conception and found that in $\mathrm{AD}$ the social self (recognition of others and understanding of the way others look at oneself) is more vulnerable than the material self (recognition of one's own body) and the spiritual self (values and philosophy of life). Fargeau et al. (2010) deemed the self to be affected when the main caregiver reported behavioral changes (compared with the premorbid status) in response to a proxy questionnaire. The majority of patients proved to be impaired in at least one domain of self, and when only one domain was affected, it was 
always the social self. In addition, autobiographical memory was more severely affected in patients who were impaired in all three self-domains than in those who were impaired in only one. Their finding echoes Gil (2007)'s conclusion that when the family says that it no longer recognizes a demented individual, it is the distress associated with the impairment of self, especially the social self, that is being expressed.

The conclusions reached by researchers on the self in $\mathrm{AD}$ seem to depend on their conceptions of self. Caddell and Clare (2010) found that scientists who regard self as a single and indivisible entity argue that it progressively deteriorates, while those who regard self as a multifaceted entity conclude that some parts of self remain intact despite the disease. Thus, instead of focusing on self, some authors have chosen to assess sense of identity, in other words, self as it is represented in one's mind. Their aim was to examine whether AD patients are aware of themselves and, if so, whether their vision of themselves is distorted, that is, not consistent with what they have become over time.

Addis and Tippett (2004) assessed sense of identity in mild to moderate AD through the Twenty Statements Test (Kuhn \& McPartland, 1954), the identity component of the Tennessee Self-Concept Scale (TSCS; Fitts \& Warren, 1996) and the Autobiographical Memory Interview (Kopelman, Wilson, \& Baddeley, 1990). They found that AD patients in the mild to moderate stages of dementia had a weaker, vaguer, and less definite sense of identity than controls. Moreover, the decline in the strength and quality of their sense of identity was related to the impairment of their autobiographical memory for childhood and early adulthood. Naylor and Clare (2008) also administered the TSCS to 20 AD patients in the early stage of dementia, but they did not find any significant links between sense of identity and autobiographical memory when they controlled for the level of cognitive decline. However, the absence of healthy control participants in their study prevented them from 
reaching any firm conclusions about sense of identity per se in AD patients (see also Caddell and Clare, 2011b).

Klein, Cosmides, and Costabile (2003) asked Patient KR, a women in the severe stage of AD (MMSE: 9), to judge a list of personality traits for self-descriptiveness (e.g., "Does this describe you: Stubborn? Yes or No?") in two identical sessions two weeks apart. Subsequently, KR's daughter and her caregiver at the assisted living facility were also asked to rate KR on the same traits. The authors showed that KR's trait self-knowledge was preserved and remained accessible despite her difficulty retrieving ordinary information from semantic memory, such as the names of everyday objects and places. However, even though KR's test-retest ratings were reliable, indicating the stability of her sense of identity, her trait self-knowledge reflected her premorbid personality, rather than her current one. Her ratings did not match those provided by either her daughter or her caregiver, who reported that KR's personality had changed dramatically as the disease progressed. For Klein et al. (2003), the persistence of sense of identity in $\mathrm{AD}$ could be explained by the relative preservation of semantic self-representations, which include personality traits. They argued that semantic trait self-knowledge is the most resistant to the cognitive chaos resulting from developmental and/or environmental damage to the brain, but failed to offer any explanation for this, concluding that it remained a mystery (Klein \& Lax, 2010). To sum up, research suggests that some components of self in AD patients are increasingly damaged as the disease progresses, while others seem to be preserved, at least in part. However, very few studies have attempted to assess sense of identity in $\mathrm{AD}$, probably because of the lack of suitable assessment tools for patients who have such difficulty communicating. Thus, in order to examine sense of identity and state if it remains the same over a two week interval, even in the advanced stages of AD, we specifically designed several tasks, adapting them from the existing ones in order to make them suitable for these patients. 


\section{Material and Methods}

\subsection{Participants.}

Sixteen AD patients and 16 healthy elderly controls (ECs) were recruited from the Les Pervenches care home in Biéville-Beuville (Normandy, France) where they are residents. Participants were aged 75-95 years. All the patients had been diagnosed with probable AD according to the NINCDS-ADRDA criteria (McKhann et al., 1984). They were in the mild to severe stages of the disease, according to their scores on the MMSE, which ranged from 5 to 23. Three patients were in the mild stage (MMSE score higher than 20), 10 patients in the moderate stage (MMSE from 20 to 10) and 3 patients in the severe stage of the disease (MMSE score less than 10). Selection criteria were limited to the age and correct comprehension of simple sentences, as judged by a geriatrician (OL). No subject who was invited to participate in the study refused. ECs did not have any memory complaints or signs of depression. None of the participants had a history of alcoholism, head trauma or psychiatric illness.

\subsection{General procedure.}

Sense of identity was assessed by asking participants to provide a spontaneous selfdefinition (the I-AM test) and a rating of self-descriptive statements (the IMAGE test). In addition, we asked to the participants a subjective estimation of their own age which is one of self-representations that needs to be continuously updated during the life. In order to examine the reliability of participants' reports on sense of identity, the entire assessment was repeated a fortnight later. In between these two sessions, we measured the patients' and ECs' cognitive efficiency on Signoret's cognitive battery (BEC96; Signoret, 1988), which includes several subtests assessing recall, learning, orientation, mental manipulation, mental problem-solving, verbal fluency, object-naming, and visual reproduction (maximum score: 96). The same 
examiner (MLE) carried out all the interviews, as well as the cognitive tests. She made sure that the participants properly understood each test, while providing appropriate assistance (e.g., rewording the sentences) when necessary.

\subsection{The I-AM (Identity-Alzheimer Moderate) test.}

The I-AM test is an adaptation of the Twenty Statements, which requires participants to complete 20 written sentences beginning with "I am". Owing to the cognitive difficulties of AD patients, we designed a modified version of the test in which participants had to complete 10 "I am..." statements orally. Participants were encouraged to describe who they are and their own perceptions of themselves without worrying about the importance of their responses. The test took the form of a private discussion with the examiner, in which the participants gave 10 descriptions of themselves. The examiner wrote down the participants' answers and, if necessary, encouraged them to continue in as neutral a way as possible. No time limit was imposed, but in practice the test lasted less than 20 minutes.

Each response was classified as idiocentric, small group, large group, or allocentric, according to the coding scheme proposed by Watkins and coworkers (1997). Idiocentric responses reflect the independent type of self-construal, that is, statements refer to personal qualities, attitudes and states that are not related to other people (see Table 1). By contrast, small-group and large-group statements reflect interdependent construal of self. Allocentric responses are socially oriented by nature, as they involve interdependence and other people's viewpoints. Idiocentric responses were further divided into physical feature, personality trait, and preference subcategories, while allocentric responses were divided into personality trait and preference subcategories (Cousins, 1989). Finally, if applicable, we noted the emotional valence associated with each statement. Examples of statements belonging to the different categories or subcategories, and with different emotional valences are given in Table 1. Two 
experts (MLE and AJ) rated each statement provided by participants until a consensus was reached.

Table 1. Coding Scheme for the I-AM Test

\begin{tabular}{llll}
\hline Categories & Subcategories & Emotional valence & Example
\end{tabular}

Idiocentric Physical feature $\quad$ Positive, negative or neutral I am big-boned

Idiocentric Personality trait Positive, negative or neutral I am an enthusiastic person

$\begin{array}{llll}\text { Idiocentric } & \text { Preference } & \mathrm{Na} & \text { I am a person who likes to } \\ & & \text { travel } \\ \text { Small group }- & \mathrm{Na} & \text { I am a grandfather } \\ \text { Large group }- & \mathrm{Na} & \text { I am a pensioner }\end{array}$

Allocentric Personality trait Positive, negative or neutral I am a sociable person

$\begin{array}{lll}\text { Allocentric } & \text { Preference } & \text { I am a person who likes to } \\ \text { be heeded }\end{array}$

Note. Na: not applicable.

The following scores were calculated for each session: the overall number of statements generated, the number of responses belonging to each category or subcategory, and their emotional valence (positive, negative or neutral,), as well as the number of different categories (maximum 4) and subcategories (maximum 7) of responses. We also counted the numbers of sentences in which participants clearly stated that they no longer knew who they were, and sentences that were obviously erroneous at the time of testing (e.g., "I am a student"), but which could have been true in the past. 


\subsection{The IMAGE test.}

The IMAGE test was adapted for use with $\mathrm{AD}$ patients even in the advanced stage of dementia from the second edition of the TSCS (TSCS2), the Questionnaire of SelfRepresentations (QSR; Duval et al., 2012), and the revised version of the Self-Consciousness Scale (Scheier \& Carver, 1985). The structure of the IMAGE test was based on the TSCS2, which measures three components of the self-concept (identity, behavior, and selfsatisfaction) in five different domains (moral-ethical, social, personal, physical, and family). The IMAGE test is composed of 24 descriptive statements, 21 of which refer to the above three self-concept components. Each component contains seven statements, each belonging to one of seven self-concept domains. These include the five TSCS2 domains and two others from the QSR (cognition and emotion). A fourth self-concept component, referring to private self-consciousness, includes the remaining three descriptive statements, which were taken from the revised version of the Self-Consciousness Scale.

The translation of the original English sentences was checked by a bilingual English/French speaker. All the sentences were worded so that they would easily be understood by the $\mathrm{AD}$ patients and pretests of comprehension were made in a different sample of patients. Regarding the adaptation of the TSCS2, self-statements unsuitable for the context were not used (e.g. I'm not good at the work I do) and the number of items was reduced compared to the original version but we respected the distribution of the self-descriptions within the five domains. Changes compared to the direct translation concern low frequency words and complex grammatical structures such as double negative. All the descriptive statements were affirmative, but half were positive ("I am a reliable person") and half were negative ("I am a rather unhappy person"). All the test statements are provided in the Appendix. The examiner presented each descriptive statement in the form of a question to the participant and asked her/him to reply whether it was true or false. The examiner then asked 
the participant to say whether the statement was totally true/false or only partly so. Task's instructions were repeated when necessary. Responses were recorded by the examiner on a 4point Likert-like scale with the following anchor points: Totally false (1), Partly false (2), Partly true (3) and Totally true (4). The scoring procedure was adapted to take the general meaning of the sentences into account.

Different scores were calculated from the participants' responses recorded in the first session. The total score (sum of all the items, maximum 96) reflected the individual's overall sense of identity and associated level of self-esteem, indicating whether he or she tended to hold a generally positive or a generally negative self-view. Subscores were also calculated for each of the four self-concept components. The identity subscore (maximum 28, i.e., 7 x 4) reflected how the participants described themselves when they referred to who they were. The behavioral subscore (maximum 28) reflected how the participants described themselves when they referred to how they act. The self-satisfaction subscore (maximum 28) reflected the way the participants described themselves when they referred to how content they were with themselves. The private self-consciousness subscore (maximum 12, i.e. 3 x 4) reflected the way the participants described themselves when they referred to their ability to observe and analyze themselves, especially for aspects that were personal in nature and not easily accessible to the scrutiny of others, such as their own feelings. We also reported the number of definite responses for each of the four components of the self-concept (responses scored 1 or 4) and the total number of definite responses. Table 2 indicates the structure and scores of the IMAGE test. 
Table 2. Structure and Scores of the IMAGE Test

\begin{tabular}{|c|c|c|c|}
\hline Components of the self-concept & Domains (Sources) & Number of items & Scores \\
\hline Identity & cognition, emotion (QSR) & & \\
\hline \multirow{2}{*}{ Behavior } & physical, family (TSCS2), & & Number of definite responses (max. 7) \\
\hline & cognition, emotion (QSR) & & \\
\hline Self-satisfaction & Moral-ethical, social, personal, & 7 & Self-satisfaction subscore (max. 28) \\
\hline Private self-consciousness & & & Number of definite responses (max. 3) \\
\hline \multirow[t]{2}{*}{ Total } & - & 24 & Total score (max. 96) \\
\hline & & & Total number of definite responses (max. 24) \\
\hline
\end{tabular}

Note. Na: not applicable; QSR: Questionnaire of Self-Representations; TSCS2: Tennessee Self-Concept Scale; second edition. 


\subsection{Subjective age.}

To obtain the participants' subjective estimations of their age, we simply asked the question "How old are you?" The participants' chronological ages were obtained from their medical records. For each participant, we computed the difference between the chronological and subjectively estimated ages, with a negative value indicating when a subjective age was lower than the chronological one.

\subsection{Comparison of sense of identity between the two sessions.}

To assess the reproducibility of the responses on the I-AM test, we compared the numbers of categories (maximum 4) and subcategories (maximum 7) of responses, as well as the numbers of responses belonging to each category and subcategory, and for each emotional valence (positive, negative or neutral) produced in Session 1 and Session 2. We also computed the number of sentences that referred to the same idea in both sessions, distinguishing those that were rephrased between the two sessions from those that were repeated verbatim.

Regarding the IMAGE test, we compared responses between the two sessions and calculated the number of 1) responses that were exactly the same (identical responses), 2) responses that differed between the two sessions but retained the same meaning (similar responses, such as totally true and partly true), and 3) opposite responses (contrasting responses, such as totally true and partly false).

Regarding the subjective estimation of age, for each participant, we computed the difference between the subjective ages expressed in each session.

Finally, in the AD group, we calculated Spearman's rank correlation coefficient to examine the relationship between the reliability of patients' responses on the IMAGE test across the 
two sessions and the severity of their cognitive deterioration, as measured by the BEC96 score.

\section{Results}

\subsection{Demographic and general cognitive data.}

The patient and EC groups did not differ significantly in terms of sex, $\chi 2(1)=1.14, p=$ $.28, \phi_{\mathrm{c}}=0.19$, age, $t(30)=-1.42, p=.16, \mathrm{~d}=0.50$, or years of education, $t(30)=-1.14, p=$ $.26, \mathrm{~d}=0.40$. As expected, there were significant differences between the groups on the total BEC96, $t(29)=-7.02, p<.001, \mathrm{~d}=2.52$, and MMSE scores, $t(30)=-6.88, p<.001, \mathrm{~d}=2.43$ (Table 3).

Table 3. Mean (Standard Deviation) Demographic and General Cognitive Data of the AD and EC Groups
AD group
EC group

$N(\mathrm{M} / \mathrm{F})$

Age (years)

Education (years)

MMSE (total score)

Signoret's cognitive battery (BEC96; total score)

$16(1 / 15)$

$85.1( \pm 4.5)$

$6.9(0.3)$

$14.0( \pm 5.8)$

$24.9( \pm 2.6)$

Note. MMSE: Mini-Mental State Examination.
$33.4( \pm 22.2) \quad 76.8( \pm 9.2)$ 


\subsection{Sense of identity (Session 1).}

\subsubsection{The I-AM test.}

There was a difference between the numbers of self-descriptions given by the AD and EC groups, $t(30)=-2.60, p<.02, \mathrm{~d}=0.92$, with $\mathrm{AD}$ patients generating fewer items $(\mathrm{M}=6.37$, $\mathrm{SD}=2.09)$ than $\mathrm{ECs}(\mathrm{M}=8.06, \mathrm{SD}=1.53)$. We used chi-square tests to investigate whether the numbers of individuals referring to large numbers of categories or subcategories differed between the groups. In order to conduct valid chi-square tests, the cell values were collapsed. There was no difference between the $\mathrm{AD}$ and $\mathrm{EC}$ groups in terms of the numbers of participants who gave responses belonging to fewer than four or four categories, $\chi^{2}(1)=1.25$, $p=.26, \phi_{c}=0.20$, nor fewer than five or five or more subcategories, $\chi^{2}(1)=0.58, p=.44, \phi_{c}$ $=0.13$.

A qualitative analysis of the statements they produced showed that six of the AD patients (five of whom had MMSE scores below 13) produced sentences indicating that they no longer really knew who they were (e.g., "I don't remember myself"; 15/102 responses). None of the ECs produced this type of response. Four of the AD patients (MMSE scores: 5, 10, 20 and 21) produced self-statements that were obviously erroneous at the time of testing (e.g., "I am still in my grocer's store"; 12/102 responses). None of the ECs produced this type of response.

There was no difference between the AD and EC groups in terms of response distribution across the four categories (idiocentric, small group, large group, and allocentric), $\chi^{2}(3)=4.57$, $p=.21, \phi_{\mathrm{c}}=0.14$ (Table 4). Both groups produced more idiocentric responses than responses belonging to the other three categories. There was also no difference between the AD and EC groups in the distribution of responses across the seven subcategories, $\chi^{2}(6)=8.73, p=.19, \phi_{c}$ $=0.19$. We failed to find any difference between the AD and EC groups in the distribution of responses across emotional valence, $\chi^{2}(2)=0.77, p=.68, \phi_{c}=0.08$ (Table 5), with both 
groups producing more positive responses than neutral and negative responses put together. Positive responses made up $73.9 \%$ of the responses that could be scored for emotional valence in the $\mathrm{AD}$ group and $78.7 \%$ in the EC group.

Table 4. Numbers of Idiocentric, Small Group, Large Group, and Allocentric Responses Provided by the AD and EC Groups

\begin{tabular}{llllll}
\hline Response category & Idiocentric & Small group & Large group & Allocentric & Total \\
AD group & 51 & 9 & 24 & 18 & 102 \\
& & & & & \\
\hline EC group & 65 & 22 & 21 & 20 & 128 \\
\hline
\end{tabular}

Table 5. Numbers of Positive, Neutral and Negative Responses Provided by the AD and EC Groups

\begin{tabular}{lllll}
\hline Response valence & Positive & Neutral & Negative & Total \\
AD group & 34 & 4 & 8 & 46 \\
& & & & \\
\hline EC group & 48 & 6 & 7 & 61 \\
\hline
\end{tabular}

\subsubsection{The IMAGE test.}

The total score and subscores of the IMAGE test are set out in Table 6. An independent samples $t$ test did not show any significant difference between the total scores obtained by each group, $t(30)=1.12, p=.27, \mathrm{~d}=0.40$. Nor was there any significant difference between the groups on the identity, $t(30)=-0.07, p=.94, \mathrm{~d}=0.03$, behavior, $t(30)=0.57, p=.57, \mathrm{~d}=$ 0.20 , and private self-consciousness subscores, $t(30)=0, p=1, \mathrm{~d}=0.00$. By contrast, the 
groups differed significantly on the self-satisfaction subscore, $t(30)=2.35, p<.03, \mathrm{~d}=0.83$, with the AD group scoring more highly.

Table 6. Scores of the AD and EC Groups on the IMAGE Test

\begin{tabular}{lll}
\hline & AD group & EC group \\
\hline Total score & $80.69( \pm 0.83)$ & $78.12( \pm 5.63)$ \\
Identity subscore & $24.94( \pm 2.69)$ & $25.00( \pm 2.07)$ \\
Behavior subscore & $22.63( \pm 3.40)$ & $21.94( \pm 3.43)$ \\
Self-satisfaction subscore* & $24.88( \pm 2.03)$ & $22.94( \pm 2.59)$ \\
Private self-consciousness subscore & $8.25( \pm 2.29)$ & $8.25( \pm 2.14)$ \\
\end{tabular}

Note. ${ }^{*}$ indicates a significant difference between the AD and EC groups (Student's $t$ test, $p<$ $.03)$.

Regarding the total number of definite responses (responses scored 1 or 4 ), an independent samples $t$ test did not reveal any significant difference between the AD and the EC groups, $t(30)=-1.20, p=.24, d=0.42$ (Table 7). Regarding the number of definite responses for each of the self-concept components, Mann-Whitney $U$ tests did not show any significant difference for identity, $\mathrm{z}=-0.96, p=.34, \mathrm{r}=0.17$, behavior, $\mathrm{z}=-0.83, p=.41, \mathrm{r}=0.15$, or self-satisfaction, $\mathrm{z}=-0.47, p=.64, \mathrm{r}=0.08$, between the two groups. By contrast, the two groups differed significantly on the private self-consciousness component, $\mathrm{z}=-2.09, p<.04, \mathrm{r}$ $=0.37$ with fewer definite responses being provided by the AD patients. 
Table 7. Mean (Standard Deviation) Numbers of Definite Responses in the IMAGE Test

\begin{tabular}{lll}
\hline Number of definite responses & AD group & EC group \\
\hline Total & $16.38( \pm 3.63)$ & $17.69( \pm 2.44)$ \\
Identity component & $5.13( \pm 1.67)$ & $5.25( \pm 1.06)$ \\
Behavior component & $4.81( \pm 1.42)$ & $5.06( \pm 1.24)$ \\
Self-satisfaction component & $4.81( \pm 1.05)$ & $5.13( \pm 1.63)$ \\
Private self-consciousness component* & $1.63( \pm 0.72)$ & $2.25( \pm 0.68)$
\end{tabular}

Note. * indicates a significant difference between the AD and EC groups (Mann-Whitney $U$ test, $p<.04)$.

\subsubsection{Subjective age.}

For the subjective age estimation task, one patient's response was excluded from the analysis because of her perseveration on her year of birth. For two other patients who produced responses implying a range (e.g., "I am 40-50 years old"), we used the means of the two values. One-sample $t$ tests showed that in Session 1, the mean difference between subjective age estimation and chronological age differed significantly from 0 in the AD group $(\mathrm{M}=-13.69$ years, $\mathrm{SD}=16.36) t(14)=-3.24, p<.006, \mathrm{~d}=0.84$, but not in the EC group $(\mathrm{M}$ $=-0.14$ years, $\mathrm{SD}=0.47) t(15)=-1.23, p=.24, \mathrm{~d}=0.30$.

\subsection{Reliability of participant's reports on sense of identity over the two sessions.}

Regarding the I-AM test, there were no differences in the numbers of categories, $\chi^{2}(3)=$ $0.30, p=.96, \phi_{c}=0.04$, or subcategories, $\chi^{2}(6)=0.97, p=.99, \phi_{c}=0.07$, referred to between Sessions 1 and 2 in the AD group. Nor was there any differences in the numbers of 
emotionally valenced responses, $\chi^{2}(2)=4.06, p=.13, \phi_{c}=0.22$, between the two sessions in AD patients. Results were the same for ECs, with no differences in the numbers of categories, $\chi^{2}(3)=3.46, p=.32, \phi_{c}=0.11$, or subcategories, $\chi^{2}(6)=9.88, p=.13, \phi_{c}=0.19$, between Sessions 1 and 2, and no difference in the numbers of emotionally valenced responses, $\chi^{2}(2)=$ $4.92, p=.09, \phi_{\mathrm{c}}=0.20$ between the two sessions.

A total of 25 sentences referred to the same idea in both sessions ( $24.5 \%$ of the items) in the AD group, and 26 in the EC group (20.3\% of the items). Interestingly, a significant difference was found between the groups in the number of sentences that were rephrased and those that were repeated verbatim, $\chi^{2}(2)=24.33, p<.001, \phi_{c}=0.69$ : whereas AD patients repeated 24 of the 25 sentences verbatim in the second session, EC participants rephrased 23 of the 26 sentences.

For the IMAGE test, we counted the numbers of identical (responses exactly the same in both sessions), similar (responses that differed between the two sessions but retained the same meaning), and opposite responses (responses with contrasting meanings) given by the participants in Sessions 1 and 2. No difference was found in the distribution of these three types of responses across the $\mathrm{AD}$ and EC groups, $\chi^{2}(2)=0.60, p=.74, \phi_{\mathrm{c}}=0.03$, with identical responses being the most frequent for both the $\mathrm{AD}(63.4 \%)$ and $\mathrm{EC}(58.9 \%)$ groups (Table 8).

Results of the correlation analyses indicated a significant positive correlation between BEC96 scores and the number of identical responses on the IMAGE test ( $r h o=0.47, p<.04)$, as well as a significant negative correlation between BEC96 scores and the number of similar responses on the IMAGE test $(r h o=-0.44, p<.05)$. The correlation between BEC96 scores and the number of opposite responses on the IMAGE test was not significant $(r h o=-0.27, p=$ $.15)$. 
Table 8. Numbers of Identical, Similar, and Opposite Responses Provided Across the Two Sessions of the IMAGE Test by the AD and EC Groups

\begin{tabular}{lllll}
\hline & Identical & Similar & Opposite & Total \\
\hline AD group & 245 & 60 & 79 & 384 \\
EC group & 239 & 68 & 77 & 384 \\
\hline
\end{tabular}

Regarding subjective age estimation, the data for two patients were excluded from the analysis because of their perseverative responses referring to their year of birth (in the first or second session). A one-sample $t$ test showed that the difference between the subjective age estimations given in Sessions 1 and 2 did not significantly differ from 0 in either the AD group $(\mathrm{M}=0.96, \mathrm{SD}=14.00), t(13)=0.26, p=.80, \mathrm{~d}=0.07$, or the $\mathrm{EC}$ group $(\mathrm{M}=0.19, \mathrm{SD}$ $=1.05), t(15)=0.72, p=.49, \mathrm{~d}=0.95$.

\section{Discussion}

The aim of our study was to examine sense of identity in AD and whether AD patients' reports remain the same within a fortnight, knowing that they suffer from a profound memory deficit affecting both episodic and semantic memory. We assessed a group of mild to severe $\mathrm{AD}$ patients and a group of matched elderly healthy control participants, both living in the same institution. We adapted self-representation tests to take account of the AD patients' cognitive difficulties and administered them on two separate occasions, a fortnight apart.

The AD patients, even those in the severe stage of the disease, satisfactorily completed the I-AM test, indicating that their sense of identity broadly persisted despite the disease. Interestingly, we did not observe any difference between the two groups in terms of the numbers of categories and subcategories referred to in the I-AM test, suggesting that sense of 
identity retains much of its complexity in AD patients. Although Addis and Tippet (2004) reported the same result, using the Twenty Statements Test with an alternative category coding procedure, they reached a different conclusion, speculating that the prompts they used might have encouraged the controls and patients to evoke comparable categories of selfdescriptions. By contrast, the participants in our study were encouraged to generate selfdescriptions without any indications that could bias access to spontaneous self-descriptions and their associated levels of complexity. The AD patients and EC participants made equal reference to the various categories and subcategories of responses when they generated descriptions of themselves in the I-AM test. They also provided comparable numbers of emotionally valenced self-descriptions in the I-AM test. Taken together, these results argue in favor of a comparable structure of sense of identity in the AD patients and EC participants.

The only difference between the two groups concerned the number of self-descriptions produced in the I-AM test. In line with the literature (Addis \& Tippet, 2004), AD patients provided fewer self-descriptions than EC participants, suggesting that their sense of identity may have been weakened by the disease. The difference between the AD and EC groups in terms of numbers of self-descriptions could however be explained, at least in part, by their language and initiation deficits. Some of the $\mathrm{AD}$ patients produced statements referring to a loss of sense of identity. However, these statements represented less than $15 \%$ of the total number of self-descriptions. A complementary non-parametric statistical analysis indicated that there was no difference between the six patients that produced such statements and the rest of the $\mathrm{AD}$ group in respect to demographic and general cognitive data. Regarding the measures of sense of identity (session 1) the only significant difference between the two AD patients' subgroups was for the private self-consciousness subscore of the IMAGE test $(\mathrm{z}=$ 2.17, $p<.04, \mathrm{r}=0.38$ ) with the six patients that produced statements referring to a change in their sense of identity in the I-AM test scoring lower $(M=6.50, \mathrm{SD}=2.43)$ than the rest of 
the AD group $(\mathrm{M}=9.30, \mathrm{SD}=1.49)$. Patients who expressed their difficulties to describe themselves in the I-AM test reported a less positive view of their private self-consciousness in the IMAGE test. These results underline the coherence of these measures. Regarding the reliability of the reports of the sense of identity across the two sessions, results of each subgroup were the same as those of the whole AD group.

Regarding the results for the IMAGE test in Session 1, the two groups did not differ on the total number of definite responses they provided (i.e., responses scored 1 or 4). Most of the self-evaluations performed by the AD patients and EC participants were definite (about 2/3 of all statements), indicating a sense of identity that could be regarded as well-defined. At first sight, this result would appear to contradict Addis and Tippett's (2004) finding. However, methodological aspects could partially explain this difference. In our study, in order to overcome the AD patients' difficulty using the response scales, the participants' selfevaluations were recorded by the examiner, who then converted their oral responses to ratings on a 4-point scale. This procedure may have pushed participants to take a stand, as the statements were presented in the form of questions requiring them to say whether they were true or false. In Addis and Tippet's (2004) procedure, each statement was rated on a 5-point scale by the participants themselves, possibly leading them to be drawn to responses in the middle of the scale (regarded as vague), especially if they were suffering from comprehension or initiation deficits.

Regarding the private self-consciousness components, AD patients appeared to be less definite than ECs. The private self-consciousness component refers to an individual's ability to observe and analyze him or herself, especially on those aspects that are personal in nature and not easily accessible to the scrutiny of others, such as their own feelings. Selfrepresentations belonging to the self-consciousness component may be less clear-cut in $\mathrm{AD}$ patients, as they are rarely activated, and are thus less resistant to neural and cognitive 
damage. In addition, the self-consciousness component probably involves episodic memory, as we can only notice changes in our mood if we remember our earlier emotional state, just as thinking about oneself relies on the ability to coherently develop and hold a subject in one's mind over a certain amount of time. However, even if the AD patients in our study were indeed less self-conscious, owing to their memory deficits, what is surprising here is that they seemed to be aware of this aspect, because their self-evaluation in this respect was less definite than that of their healthy peers. This is all the more surprising given that their selfsatisfaction score was higher than that of the ECs, suggesting that they either were not aware of their cognitive and everyday life difficulties (see below) or else just did not give them that much importance. We cannot exclude the possibility that both mechanisms were at work at the same time: while patients may have a more or less explicit awareness of their impairment, self-defense mechanisms may generate a coherent and positive sense of identity, in order to ensure that life remains tolerable despite the disease.

The total scores on the IMAGE test suggest that the AD patients' self-representations were just as positive as those of the ECs. By contrast, Addis and Tippet (2004) found that the AD patients in their study had less positive self-representations than controls, probably resulting from the patients' awareness of their deficits. It is important to note that, compared with the patients included in our study, the ones assessed by Addis and Tippet were at a less severe stage of $\mathrm{AD}$, as attested by their higher MMSE scores (mean score: 19.8 versus 14.0). As reported in previous studies, AD patients' lack of consciousness about their own deficits seems to be related to the severity of their cognitive impairments (Gil et al., 2001). We can therefore hypothesize that some patients at least may have anosognosia, which could contribute to a relatively positive view of themselves. This hypothesis is supported by Naylor and Clare's (2008) study, which showed that a lower level of awareness of memory function was associated with a more positive and definite sense of identity. The other results on the 
IMAGE test lend support to the idea that the AD patients in our study had positive selfrepresentations. Although the groups did not differ on the identity, behavioral and private self-consciousness subscores, the AD patients had a higher self-satisfaction subscore (see above) compared with the ECs, further arguing in favor of their anosognosia (see Mograbi et al., 2009, for a discussion of the relationship between modified self-knowledge and anosognosia).

We found a striking difference between the AD patients and ECs on the age estimation task, with patients reporting that they were 14 years younger on average than they really were. Information about one's real age is fickle, as it needs to be updated throughout one's lifetime. Alternatively, it can be calculated by subtracting one's year of birth from the current year. Temporal disorientation would definitely result in erroneous estimations of one's age, and most of the AD patients in our study were lost in calendar time and were unable to answer the MMSE orientation questions correctly. The fact that the AD patients considered themselves to be younger than they actually were would fit in with the assumption that their sense of identity corresponded to the pre-Alzheimer's period, even if very few self-descriptions produced by the patients in the I-AM test clearly referred to their past life (e.g., "I am still in my grocer's shop"). Unlike Patient KC, who was able to update his sense of identity, probably thanks to his preserved semantic memory (Tulving, 1993), our AD patients did not seem to have updated theirs.

By repeating our assessment, we were able to demonstrate that $\mathrm{AD}$ patients' reports on sense of identity are reliable over a two weeks interval. The numbers of categories and subcategories referred to in the patients' self-descriptions, and the numbers of emotionally valenced self-descriptions given by the $\mathrm{AD}$ patients in the I-AM test remained the same across the two testing sessions. Regarding the self-descriptions that were repeated verbatim in both I-AM testing sessions, most of them were produced by patients in the severe stage of 
AD. We hypothesize that these self-descriptions may have concerned key aspects of the patients' self-concept, in other words, their sense of identity. These key self-descriptions may thus have been more resistant to cognitive damage (see Klein \& Lax, 2010), but at the same time, they may have been more rigid and rudimentary, and, like verbal stereotypes, benefited from an easy and fast mental access.

The AD patients rated the IMAGE test's statements in Sessions 1 and 2 in a similar way to the ECs, providing $63.4 \%$ identical responses compared with $58.9 \%$ for the EC group. However, the positive correlation between the number of identical responses in the IMAGE test and the cognitive battery (BEC96) scores indicates that the reliability of patients' reports on sense of identity may decrease as their dementia progresses. It is important to note that although the patients' other responses were modulated, their meaning did not change.

Finally, the age estimations they provided were surprisingly comparable across the two sessions, thus indicating that their sense of identity remained the same over a two week delay, even if did not exactly correspond to reality. When memories of past experiences are impaired, as they are in $\mathrm{AD}$, the sense of existing in the past must be dramatically compromised. Given the temporal gradient of memory impairment in AD (Piolino et al., 2003), patients may travel back to the time in their lives for which they have the clearest memories, the resulting gap being resolved by their continuity of sense of identity. The selfrepresentation of age, a component of sense of identity, is thus dependent upon subjective time and becomes tied to the best preserved episodic memories.

Our findings fit in with the description of Patient KR, who suffered from severe AD (Klein et al., 2003), and with some aspects of the amnesic patient KC (Tulving, 1993), both of whom displayed high test-retest reliability for self-ratings on personality traits. Taken together, these results suggest that sense of identity is resistant to neural and cognitive damage, such as that 
observed in severe episodic memory disorders. Some authors (see Klein \& Lax, 2010, for a review) argue that the self-representations of $\mathrm{AD}$ patients are preserved, but not updated. Thus, AD results in a sense of identity that is based on patients' pre-morbid selfrepresentations, rather than on self-representations corresponding to their current state. This speculation is supported by Klein and colleagues' (2003) findings, as KR's self-ratings on personality traits did not match those provided in a proxy questionnaire by her daughter and her caregiver (see Introduction). However, when KR's relatives were asked to rate her premorbid personality, their proxy assessments were consistent with her self-assessment. In addition, KR's test-retest ratings were reliable, showing that her sense of identity was stable, at least over a two-week interval.

Overall, the AD patients in our study were able to describe and assess themselves on two separate occasions via several different tasks specifically tailored to meet their needs. The answers they provided were comparable to those produced by the ECs and remained broadly the same across the two sessions, in both the free self-description and self-assessment tasks. Thus, the first conclusion we can draw is that $\mathrm{AD}$ patients, even in the advanced stages of dementia, do indeed possess a sense of identity which, moreover, seems to remain the same over a certain period of time. Patients may access unchanged key personality features, probably thanks to their partly preserved semantic memory and automatic access to certain knowledge. Our study revealed, however, that certain qualitative characteristics of their sense of identity differed significantly from those of ECs. AD patients may thus be unable to update their self-knowledge, mainly owing to their episodic memory deficit, eventually leading to a petrified self (Mograbi et al., 2009).

There are some limitations in the current study. The participants of both groups were almost only women which is however representative of the population in the residential care homes for elderly. Caddell and Clare (2011) results suggest a gender difference regarding 
changes in identity in mild dementia in the way that women appeared to be less confident about remaining the same as a person than men were. It is difficult to make inference regarding our findings, given that our patients were in a more advanced stage of dementia and thus, relatively anosognosic. Otherwise, we included patients in a large range of dementia severity. However, only three patients of the group had a mild dementia and complementary statistical analyses conducted without these three patients indicated the same pattern of results as the one reported in the result section (data not shown). The complex methodology used in this study limited the number of participants that we were able to include. However considering $\mathrm{p}$ values and effect sizes, the results are reliable. A third limit concerns the use of adapted tests to take into account language and working memory difficulties of the AD patients, that was essential to obtain worthwhile reports in the moderate to severe stages of dementia. Even though we were very careful to conserve the shades of meanings of the sentences of the original tests, we slightly modified the tests administration procedures that could contribute to differences with previous reports (see above). Finally it's difficult to determine how stable the sense of identity is by studying people over a period of two weeks. Our results mainly demonstrated the reliability of assessment of sense of identity in patients with important memory deficits, suggesting this stability.

\section{Conclusion and phenomenological considerations}

These results may reflect two sides of sense of identity, one being relatively general and quite stable, and therefore preserved even in the presence of extensive cognitive and neural damage, the other varying over time and with experience, and therefore more fragile, especially in the case of severe impairment of both episodic and semantic retrograde memory (Haslam et al., 2011; Piolino et al., 2003). 
These two sides of sense of identity have already been conceptualized by philosophers, notably Paul Ricœur (1990), as sameness and selfhood (see Introduction). The former refers to representations of oneself as the same being, regardless of the spatiotemporal context of one's life. The latter refers to representations of oneself as an ever changing being, with specific features yesterday and different ones today. Sameness is reflected in uncluttered, or general, self-representations, such as "I am a loner", which are more resistant to dementia, as they involve knowledge about oneself that has been forged over time and is deeply integrated. Selfhood concerns more labile aspects of identity, and thus gives rise to more transient personal semantic representations such as "I am happy" "I am a pensioner", which may be further modulated by episodic ones.

As for the link between memory and sense of identity, John Locke (1689/2001) described the mind as a blank slate at birth, which is gradually filled with senses and impressions that aggregate to form ideas of increasing complexity that help to shape identity. For Locke, identity was forged by memory, which allows a person both to know that he is the same person as he was a year ago, and to recall the experiences he has had since the previous year. Ricœur (1990) challenged this view, arguing that we are endowed with a consciousness of our self that is not the same as the one we had ten years ago. For him, sense of identity is underlain more by our current actions, occupations and experiences, even if they are not in line with our existing self-representations, than by our memories.

These two conceptions are neatly illustrated by the philosophical problem of a prince whose memory is transplanted into the body of a cobbler. The question is whether the prince remains the prince he remembers he was or whether he becomes a cobbler. For Locke, the prince remains a prince, despite inhabiting the body of a cobbler, whereas for Ricœur, if the prince starts to live a cobbler's life, he becomes a cobbler. We believe that these two visions are complementary and that sense of identity has two different sides to it that cohabit and 
make us both what we have become over time and what we are now in the present. If these two aspects are well nigh impossible to dissociate in healthy people, studies of AD patients show that this pathology impairs the updating of those self-representations that are related to the present, but not the lasting personality traits that allow AD patients to maintain a sense of identity.

The dimension of time has been highlighted in the recent model proposed by Prebble and colleagues (2012). This model delineates sense of identity along two dimensions: the objective versus subjective and the present versus temporally extended aspects of sense of identity. The four resulting components of sense of identity are argued to relate to autobiographical memory in important, but very different, ways.

In a same manner, the philosopher Edmund Husserl (1913/1950) defended the idea of a consciousness memorizing experienced or considered events and of a consciousness perceiving the former one. The first type of consciousness would perceive by means of the transversal intentionality, seeking to capture the essence of objects of perception. The second type of consciousness would be more "absolute", because perceiving the consciousness itself in the intentionality, called longitudinal. According to Husserl, the identity would emerge from the continuous memorization of consciousness' content, allowing the consciousness of oneself (Eustache, 2013). In the neuropsychological conception, autobiographical memory is also regarded as a consciousness capture of itself, defined as a narrative and continuous construction (Prebble, Addis and Tippett, 2012). Therefore autobiographical memory can be compared to the consciousness described by Husserl, being at the same time linear and introspective, active and constructed for a specific period of time. 


\section{References}

Addis, D. R., \& Tippett, L. J. (2004). Memory of myself: autobiographical memory and identity in Alzheimer's disease. Memory, 12, 56-74.

Byrne, B. M. (1996). Measuring self concept across the life span: Issues and instrumentation. Washington, DC: American Psychological Association.

Caddell, L. S., \& Clare, L. (2013). How does identity relate to cognition and functional abilities in early-stage dementia?. Neuropsychology Development, and Cognition, Section B. Aging, Neuropsychology, and Cognition, 20, 1-21.

Caddell, L. S.; \& Clare, L. (2011a). Interventions supporting self and identity in people with dementia: a systematic review. Ageing and Mental Health, 15, 797-810

Caddell, L. S., \& Clare, L. (2011b). I'm still the same person: The impact of early-stage dementia on identity. Dementia, 10, 379-398.

Caddell, L. S., \& Clare, L. (2010). The impact of dementia on self and identity: a systematic review. Clinical Psychology Review, 30, 113-126.

Cohen-Mansfield, J., Golander, H., \& Arnheim, G. (2000). Self-identity in older persons suffering from dementia: Preliminary results. Social Science and Medicine, 51, 381-394.

Conway, M. A. (2005). Memory and the self. Journal of Memory and Language, 53, 594-628.

Conway, M. A. (2009). Episodic memories. Neuropsychologia, 47, 2305-2313.

Cousins, S. D. (1989). Culture and Self-Perception in Japan and the United-States. Journal of Personality and Social Psychology, 56, 124-131. 
Davis H. J. (2004). Dementia: sociological and philosophical construction. Social Science \& Medicine, 58, 369-378.

Duval, C., Desgranges, B., de La Sayette, V., Belliard, S., Eustache, F., \& Piolino, P. (2012). What happens to personal identity when semantic knowledge degrades? A study of the self and autobiographical memory in semantic dementia. Neuropsychologia, 50, 254-265.

Eustache, M. L. (2013). Conscience, mémoire et identité. Paris : Dunod.

Fargeau, M. N., Jaafari, N., Ragot, S., Houeto, J. L., Pluchon, C., \& Gil, R. (2010). Alzheimer's disease and impairment of the Self. Consciousness and Cognition, 19, 969976.

Fazio, S., \& Mitchell, D. B. (2009). Persistence of self in individuals with Alzheimer's disease: Evidence from language and visual recognition. Dementia, 8, 39-59.

Fitts, W. H., \& Warren, W. L. (1996). Tennessee Self-Concept Scale: Manual. Los Angeles, CA: Western Psychological Services.

Folstein, M. F., Folstein, S. E., \& McHugh, P. R. (1975). "Mini-mental state". A practical method for grading the cognitive state of patients for the clinician. Journal of Psychiatric Research, 12, 189-198.

Gil, R., Arroyo-Anllo, E. M., Ingrand, P., Gil, M., Neau, J. P., Ornon, C., \& Bonnaud, V. (2001). Self-consciousness and Alzheimer's disease. Acta Neurologica Scandinavica, 104, 296-300

Gil, R. (2007). Conscience de Soi, conscience de l'Autre et démences. Psychologie \& NeuroPsychiatrie Du Vieillissement, 5, 87-99. 
Haslam, C., Jetten, J., Haslam, S. A., Pugliese, C., \& Tonks, J. (2011). 'I remember therefore I am, and I am therefore I remember': exploring the contributions of episodic and semantic self-knowledge to strength of identity. British Journal of Psychology, 102, 184-203.

Hehman, J. A., German, T. P., \& Klein, S. B. (2005). Impaired self-recognition from recent photographs in a case of late-stage Alzheimer's disease. Social Cognition, 23, 118-124.

Husserl, E. (1950). Idées directrices pour une phénoménologie (P. Ricoeur, Trans.). Paris: Gallimard. (Original work published 1913).

Husserl, E. (2003). Sur la phénoménologie de la conscience intime du temps [Partie B des leçons] (J. F. Pastureau, Trans.). Grenoble: Ed. Jérôme Millon. (Original work published 1893-1917).

James, W. (1890). The principles of psychology (vol. 1). New York: Henry Holt and Compagny.

Kihlstrom, J. F., Beer, J. S., \& Klein, S. B. (2002). Self and identity as memory. In M. R.Leary, \& J. Tangney (Eds.), Handbook of self and identity (pp. 68-90). New York: Guilford Press.

Klein, S. B. (2010). The self: As a construct in psychology and neuropsychological evidence for its multiplicity. Cognitive Science, 1, 172-183.

Klein, S. B., Cosmides, L., \& Costabile, K. A. (2003). Preserved knowledge of self in a case of Alzheimer's dementia. Social Cognition, 21, 157-165.

Klein, S. B., \& Lax, M. L. (2010). The unanticipated resilience of trait self-knowledge in the face of neural damage. Memory, 18, 918-948. 
Klein, S. B., Loftus, J., \& Kihlstrom, J. F. (1996). Self-knowledge of an amnesic patient: Toward a neuropsychology of personality and social psychology. Journal of Experimental Psychology: General, 125, 250-260.

Kopelman, M., Wilson, B. A., \& Baddeeley, A. (1990). The Autobiographical Memory Interview (AMI). Bury St. Edmunds: Thames Valley Test Company.

Kuhn, M. H., \& McPartland, T. S. (1954). An empirical investigation of self-attitudes. American Sociological Review, 19, 68-76.

Locke, J. (2001). Essai sur l'entendement humain [An Essay Concerning Human Understanding] (J. M. Vienne, Trans.). Paris: Vrin. (Original work published 1689)

McKhann, G., Drachman, D., Folstein, M., Katzman, R., Price, D., \& Stadlan, E. M. (1984). Clinical diagnosis of Alzheimer's disease: report of the NINCDS-ADRDA Work Group under the auspices of Department of Health and Human Services Task Force on Alzheimer's Disease. Neurology, 34, 939-944.

Mograbi, D. C., Brown, R. G., \& Morris, R. G. (2009). Anosognosia in Alzheimer's disease-the petrified self. Consciousness and Cognition, 18, 989-1003.

Morin, A. (2006). Levels of consciousness and self-awareness. A comparison and integration of various neurocognitive views. Consciousness and Cognition, 15, 358-371.

Naylor, E., \& Clare, L. (2008). Awareness of memory functioning, autobiographical memory and identity in early-stage dementia. Neuropsychological Rehabilitation, 18, 590-606.

Piolino, P., Desgranges, B., Belliard, S., Matuszewski, V., Lalevée, C., de La Sayette, V., \& Eustache, F. (2003). Autobiographical memory and autonoetic consciousness: triple dissociation in neurodegenerative diseases. Brain, 126, 2203-2219. 
Piolino, P., Desgranges, B., \& Eustache, F. (2009). Episodic autobiographical memories over the course of time: Cognitive, neuropsychological and neuroimaging findings. Neuropsychologia, 47, 2314-2329.

Prebble, S. C., Addis D. R., \& Tippett L. J. (2013). Autobiographical memory and sense of self. Psychological Bulletin, 139, 815-840.

Ricoeur, P. (1990). Soi-même comme un autre. Paris: Editions du Seuil.

Sabat, S. R., \& Collins, M. (1999). Intact social, cognitive ability, and selfhood: A case study of Alzheimer's disease. American Journal of Alzheimer's Disease, 14(1), 11-19.

Scheier, M. F., \& Carver, C. S. (1985). Optimism, coping, and health: assessment and implications of generalized outcome expectancies. Health Psychology: Official Journal of the Division of Health Psychology, American Psychological Association, 4, 219-247.

Signoret, J. L. (1988). Evaluation des troubles de mémoire et des désordres cognitifs associés. B.E.C. 96. Paris: IPSEN.

Stuss, D. T., Gallup, G. G., \& Alexander, M. P. (2001). The frontal lobes are necessary for 'theory of mind'. Brain, 124, 279-286.

Tulving, E. (1993). Self-knowledge of an amnesic individual is represented abstractly. In T. K. Srull \& R. S. Wyer (Eds.), Advances in social cognition (pp. 147-156). Hillsdale, NJ: Erlbaum.

Tulving, E. (2002). Chronesthesia: Awareness of subjective time. In D. T. Stuss \& R. C. Knights (Eds.), Principles of frontal lobe function (pp. 311-325). New York: Oxford University Press. 
Watkins, D., Dahlin, B., Wondimu, H. \& Yau, J. (1997). The Twenty Statements Test: some measurement issues. Journal of Cross-Cultural Psychology, 28, 626-633. 


\section{Appendix.}

\section{IMAGE test statements.}

\begin{tabular}{|c|c|c|c|}
\hline Statement & Direction & Component & Domain \\
\hline I'm an honest person & positive & Identity & Moral-ethical \\
\hline I'm sociable & positive & Identity & Social \\
\hline I'm naturally cheerful & positive & Identity & Personal \\
\hline I'm physically quite attractive & positive & Identity & Physical \\
\hline Family is important to me & positive & Identity & Family \\
\hline I'm quite serious-minded & positive & Identity & Cognition \\
\hline I'm rather a sad person & negative & Identity & Emotion \\
\hline I sometimes act immorally & negative & Behavior & Moral-ethical \\
\hline
\end{tabular}


I find it hard to talk to people I don't know

I lack self-confidence

I don't care about my appearance

I rarely quarrel with my family

I have difficult learning things

I don't often get angry

I tell lies far too often

I ought to be more friendly to people

I'm happy with who I am

I'm satisfied with the way I look

I ask too much of the people around me

I'm satisfied with my intellectual abilities negative

negative

negative

positive

negative

positive

negative

negative

positive

positive

negative

positive
Behavior

Behavior

Behavior

Behavior

Behavior

Behavior

Self-satisfaction

Self-satisfaction

Self-satisfaction

Self-satisfaction

Self-satisfaction

Self-satisfaction
Social

Personal

Physical

Family

Cognition

Emotion

Moral-ethical

Social

Personal

Physical

Family

Cognition 
I live too much in the past

I don't often think about who I am

I generally pay attention to what I feel

I find it hard to detect my mood swings negative

negative

positive

negative
Self-satisfaction

Emotion

Private Self-consciousness

Private Self-consciousness -

Private Self-consciousness - 